Check for updates

Cite this: RSC Adv., 2019, 9, 11385

\title{
Experimental and theoretical investigation of oxidative methane activation on Pd-Pt catalysts $\uparrow$
}

\begin{abstract}
Wenjie Qi, DD *abc Zehao Huang, ${ }^{a}$ Zheming Chen, ${ }^{a}{\text { Lijuan } \mathrm{Fu}^{* a} \text { and Zhigang Zhang }}^{\text {a }}$
Density functional theory (DFT) and measurements of rate are used to provide evidence for the rate determining step (RDS) and requirements of the active site for $\mathrm{CH}_{4}$ combustion on $\mathrm{Pd}$-Pt bimetallic catalysts in five different distinct kinetic regimes. These five regimes exhibit different rate equations for methane combustion due to the reaction rate constants and diverse dominant adsorbed species for these different kinetically relevant steps. Oxygen chemical potential at the $\mathrm{Pd}-\mathrm{Pt}$ surface was replaced by oxygen pressure, reflecting the kinetic coupling between $\mathrm{C}-\mathrm{H}$ and $\mathrm{O}=\mathrm{O}$ bond cleavage steps. $\mathrm{C}-\mathrm{H}$ bond cleavage occurs on different active sites in five of these kinetic regimes, evolving from vacancy-vacancy $(*-*)$ to oxygen-vacancy $\left(\mathrm{O}^{*}{ }_{-}\right)$, oxygenoxygen $\left(\mathrm{O}^{*}-\mathrm{O}^{*}\right)$ site pairs, monolayer $\mathrm{Pd}-\mathrm{O}$, and ultimately to oxide bulk with $\mathrm{Pd}-\mathrm{O}$ site pairs as the oxygen chemical potential increases. It is easier to form a metallic surface at low oxygen pressure, implying minimal O* coverage. The sole kinetically relevant step on uncovered Pd-Pt surfaces for methane combustion is $\mathrm{O}=\mathrm{O}$ bond cleavage. The supply of oxygen is obviously more important than the supply of methane in regime (I). As vacancies become less available on metallic surfaces, $\mathrm{C}-\mathrm{H}$ bond cleavage occurs via $\mathrm{O}^{*}-*$ paired sites, the energy barrier of which is much higher than that on uncovered $\mathrm{Pd}-\mathrm{Pt}$ surfaces. In this regime (II), $\mathrm{O}=\mathrm{O}$ bond cleavage is still an irreversible process because $\mathrm{O} *$ will be consumed by the rapidly formed products of methane dissociation. For the oxygen saturated surfaces in regime (III), $\mathrm{C}-\mathrm{H}$ bond cleavage occurs on two adjacent adsorbed oxygens that form $\mathrm{OH}$ and weak $\mathrm{CH}_{3}-\mathrm{O}$ bond interactions, resulting in a low activity for methane combustion. On the oxidation surfaces (IV and V), exposed metal atoms and their adjacent exposed lattice oxygen were the active sites, leading to a large decrease in $\mathrm{C}-\mathrm{H}$ bond cleavage energy barrier, deduced from both experiment and theory. The increase of the metallic oxide thickness (increase of oxygen potential) increases the methane combustion turnover rates on $\mathrm{Pd}-\mathrm{Pt}$ catalysts.
\end{abstract}

Received 28th January 2019

Accepted 23rd March 2019

DOI: $10.1039 / c 9 r a 00735 k$

rsc.li/rsc-advances relative to the initial $\mathrm{CH}_{4}$ adsorbed states, while the energy barrier for initial C-H bond cleavage on $\operatorname{Pd}(111)$ is a much larger value of $92 \mathrm{~kJ} \mathrm{~mol}^{-1}$. $^{2}$ Actually, some other metallic surfaces also exhibit a higher activation energy for initial $\mathrm{C}-\mathrm{H}$ bond cleavage of $\mathrm{CH}_{4}$ than that of $\mathrm{PdO}(101)$, such as $\mathrm{Pt}(111)$ with a value of $90 \mathrm{~kJ} \mathrm{~mol}^{-1}$ (ref. 2) and $\mathrm{Ru}(0001)$ with a value of $83 \mathrm{~kJ} \mathrm{~mol}^{-1}$. $^{3}$ Besides, PdO(101) even showed high selectivity for initial C-H bond cleavage of propane at temperatures between $\sim 150$ and $200 \mathrm{~K}^{4}$

Although the initial activity of Pd is admirable, poor stability is a restricting factor for its application. Persson et al. ${ }^{5}$ found that the stability of the Pd catalyst is very poor, and its initially high activity is difficult to maintain during operation. Some experimental results indicated that water (added or generated) \footnotetext{
may cause a significant irreversible loss in the activity of Pd catalysts. ${ }^{6,7}$ However, some other studies showed that $\mathrm{H}_{2} \mathrm{O}$ removal could lead to the best recovery of initial activity for methane combustion. ${ }^{8,9} \mathrm{Pt}$ is also a good catalyst for methane combustion, although it has a low activity under the conditions of lean combustion. Therefore, it has quite different chemical characteristics to Pd catalysts. ${ }^{10,11}$ Meanwhile, Pt has a better water and sulfur poisoning resistance capability, as compared

${ }^{a}$ Key Laboratory of Advanced Manufacturing Technology for Automobile Parts, Ministry of Education, Chongqing University of Technology, Chongqing 400050, China.E-mail: wenjieqi@cqut.edu.cn; fulijuan@cqut.edu.cn

${ }^{b}$ Department of Chemistry, Fujian Province University Key Laboratory of Green Energy and Environment Catalysis, Ningde Normal University, Ningde, 352100, People's Republic of China

'Key Laboratory of Low-grade Energy Utilization Technologies and Systems, Ministry of Education of PRC, Chongqing University, Chongqing 400044, China

$\uparrow$ Electronic supplementary information (ESI) available. See DOI: $10.1039 / \mathrm{c} 9 \mathrm{ra} 00735 \mathrm{k}$
} 
with $\mathrm{Pd}$. The Pd oxidation state is a very important parameter for methane combustion on $\mathrm{Pd} / \mathrm{Al}_{2} \mathrm{O}_{3} \cdot{ }^{12}$ Meanwhile, the superficial oxides of $\mathrm{Pt}$ also have a high activity for methane combustion, which was also predicted. ${ }^{13}$

Some previous studies ${ }^{14}$ have shown that bimetallic Pt-Pd catalysts have better catalytic activities in the presence of water. Actually, the activity of bimetallic Pd-Pt catalysts for methane combustion has been observed to increase with time when the Pt content reaches up to $35 \% .{ }^{5}$ Maione et $a l .{ }^{15}$ initially considered that Pd-Pt clusters undergo less distinct sintering, leading to a higher thermal stability compared to pure Pd clusters. Besides, the existence of $\mathrm{Pt}^{4+}, \mathrm{Pd}^{4+}$ and a metallic PdPt alloy in $\mathrm{Pd}-\mathrm{Pt} / \mathrm{Al}_{2} \mathrm{O}_{3}$ has also been identified. ${ }^{15}$ Mixed Pd-Pt oxide phases cannot be excluded, although they have never been observed, which could also explain the reason why the surface reactions on Pd and Pd-Pt catalysts are different. Besides, the bimetallic PdPt alloys possess high stability under reducing conditions. ${ }^{16}$ Furthermore, gas composition is another important aspect that has influences on the durability and activity of Pd catalysts. Bugosh et al. ${ }^{17}$ concluded that the methane combustion rate on $\mathrm{Pd}-\mathrm{Pt}$ bimetallic catalysts strongly depends on $\mathrm{O}_{2}$ concentration, especially near the stoichiometric point. Therefore, the influence of $\mathrm{O}_{2}$ concentration on the activity of $\mathrm{Pt}-\mathrm{Pd}$ catalysts is investigated in this study.

The kinetic mechanisms of methane combustion and the selectivity of chemisorbed oxygen in methane activation on Pd and Pt catalysts have been widely studied. However, the kinetic mechanisms of methane combustion on Pd-Pt bimetallic catalysts have rarely been reported, especially for the case under variable $\mathrm{CH}_{4}-\mathrm{O}_{2}$ conditions. In this paper, the effects of varying oxygen pressure from 0 to $30 \mathrm{kPa}$ at methane pressures of 2, 3, and $4 \mathrm{kPa}$ are studied. Furthermore, the kinetic consequences of $\mathrm{C}-\mathrm{H}$ bond cleavage for $\mathrm{CH}_{4}-\mathrm{O}_{2}$ catalysis on $\mathrm{Pd}-\mathrm{Pt}$ catalysts are investigated. Also, the cases of increasing oxygen pressures are studied. Five kinds of catalysts with different amounts of Pt and Pd via both theory and experiment were analyzed, obtaining distinct reaction pathways for methane $\mathrm{C}-\mathrm{H}$ bond cleavage.

\section{Methods}

\subsection{Details of computation}

In this study, the generalized gradient approximation (GGA) and the Perdew-Burke-Ernzerhof (PBE) functional were adopted to perform the DFT calculations. Cambridge Sequential Total Energy Package 8.0 (CASTEP 8.0) program package ${ }^{18}$ was used to determine the most stable structure and obtain the activation energy. The optimal geometry, accurate simulation and electronic structures were acquired with a $380 \mathrm{eV}$ plane wave cut-off energy. $6 \times 6$ $\times 1$ and $6 \times 6 \times 6$ Monkhorst-Pack $k$-points were used for geometry optimization of the surfaces and the primitive cells, respectively. Besides, the ultrasoft pseudopotential (US-PP) was adopted to describe the interactions between core and valence electrons. Fermi smearing with a value of $0.2 \mathrm{eV}$ was utilized in this study. The energy convergence criteria for energy, self-consistent field, maximum displacement and maximum force, respectively, with values of $2.0 \times 10^{-5} \mathrm{eV}$ per atom, $2.0 \times 10^{-6} \mathrm{eV}$ per atom, 2.0 $\times 10^{-3} \AA$ and $0.05 \mathrm{eV} \AA^{-1}$ were utilized. Finally, the transition states were determined by using the method of linear synchronous transit/quadratic synchronous transit (LST/QST). ${ }^{19}$

According to previous results of XRD patterns, $\mathrm{Pd}_{x} \mathrm{Pt}_{1-x} \mathrm{O}$ is the only bulk oxide, namely some Pd atoms were replaced by the same number of Pt atoms. ${ }^{9}$ To investigate the thermodynamic stability of $\mathrm{Pd}_{x} \mathrm{Pt}_{1-x} \mathrm{O}$, its Gibbs free energy of formation was calculated with DFT. Even though the transformation processes of the metal to metallic oxide are difficult to calculate, transformation temperature is easy to acquired via the calculation of the Gibbs free energy of formation. The approximation form for the Gibbs free energy of formation of $\mathrm{Pd}_{x} \mathrm{Pt}_{1-x} \mathrm{O}$ can be given by: ${ }^{20,21}$

$$
\begin{aligned}
\Delta G(T, p, x)= & E_{\text {oxide }}-\left[x E_{\mathrm{Pd}}+(1-x) E_{\mathrm{Pt}}\right] \\
& -0.5\left[E_{\mathrm{O}_{2}}+\tilde{\mu}_{\mathrm{O}_{2}}\left(p^{0}, T\right)+k_{\mathrm{B}} \ln \frac{p}{p^{0}}\right] \\
& +T k_{\mathrm{B}}\left(x \ln \left(\frac{x}{1-x}\right)+\ln (1-x)\right)
\end{aligned}
$$

where $E_{\text {oxide }}$ is the total energy of the mixed oxide per metal atom. $E_{\mathrm{Pt}}$ and $E_{\mathrm{Pd}}$ are the energies of a bulk Pt and Pd atom, respectively. The last two terms are the oxygen chemical potential and the mixing entropy, respectively. Besides, $\tilde{\mu}_{\mathrm{O}_{2}}\left(p^{0}, T\right)$ is the chemical potential, which is measured at standard atmospheric pressure. The difference of the standard oxygen chemical potential is estimated by other research as: ${ }^{21}$

$$
\Delta \tilde{\mu}_{\mathrm{O}_{2}}\left(p^{0}, T\right)=-0.1159 T+10.0775
$$

\subsection{Catalyst synthesis and analysis}

Bimetallic catalysts were prepared by incipient wetness impregnation of $\gamma-\mathrm{Al}_{2} \mathrm{O}_{3}$ with mixed solutions of $\mathrm{PtCl}_{4}$ and $\mathrm{Pd}\left(\mathrm{NO}_{3}\right)_{2}$. Using the incipient wetness impregnation method, $\mathrm{Pd}-\mathrm{Pt} / \gamma-\mathrm{Al}_{2} \mathrm{O}_{3}$ bimetallic catalysts with varied compositions were prepared: $\mathrm{Pd}_{1.0} \mathrm{Pt}_{0} / \gamma-\mathrm{Al}_{2} \mathrm{O}_{3}, \mathrm{Pd}_{0.75} \mathrm{Pt}_{0.25} / \gamma-\mathrm{Al}_{2} \mathrm{O}_{3}, \mathrm{Pd}_{0.5} \mathrm{Pt}_{0.5} /$ $\gamma-\mathrm{Al}_{2} \mathrm{O}_{3}, \mathrm{Pd}_{0.25} \mathrm{Pt}_{0.75} / \gamma-\mathrm{Al}_{2} \mathrm{O}_{3}$ and $\mathrm{Pd}_{0} \mathrm{Pt}_{1.0} / \gamma-\mathrm{Al}_{2} \mathrm{O}_{3}$. The catalysts achieved a loading of around $188 \mu \mathrm{mol}$ metallic atoms per gram of catalyst power. Then, all samples were calcined at $923 \mathrm{~K}$ after drying for over $10 \mathrm{~h}$ in air.

A thermogravimetric analyzer (TG 209F3) was used to measure the decomposition and reformation of these metallic oxides. Inductively coupled plasma atomic emission spectroscopy (ICP-AES) was used to determine the amounts of metals on these catalysts. The dispersion of $\mathrm{Pd}-\mathrm{Pt}$ bimetallic clusters in these samples was determined by $\mathrm{CO}$ adsorption measurements. The measured and following calculated values of these catalysts are summarized in Table 1 . The Pd-Pt dispersion of these catalysts was used to calculate the pre-exponential factor and apparent activation energy for methane combustion.

\section{Results and discussion}

\subsection{Metallic oxide-to-metal transformation of Pd-Pt catalysts}

$20 \% \mathrm{O}_{2} / \mathrm{N}_{2}$ was used in the phase transformation experiments for all catalysts. A continuous flow of the gas mixture at 200 
Table 1 Actual metal loading, CO uptake and metal cluster dispersion of the different catalysts

\begin{tabular}{llllll}
\hline Sample & Actual wt\% Pd & Actual wt\% Pt & $\begin{array}{l}\mu \text { mol CO uptake } \\
\text { per g catalyst }\end{array}$ & $\begin{array}{l}\text { Pd-Pt dispersion (\%) } \\
\text { from CO uptake }\end{array}$ & $\begin{array}{l}\text { Average cluster } \\
\text { diameter (nm) }\end{array}$ \\
\hline $\mathrm{Pd}_{1.0} \mathrm{Pt}_{0}$ & 2.0 & 0 & 9.7 & 9.3 & 12.0 \\
$\mathrm{Pd}_{0.75} \mathrm{Pt}_{0.25}$ & 1.7 & 0.9 & 11.3 & 9.4 & 11.6 \\
$\mathrm{Pd}_{0.50} \mathrm{Pt}_{0.50}$ & 1.0 & 1.8 & 9.8 & 7.2 & 15.8 \\
$\mathrm{Pd}_{0.25} \mathrm{Pt}_{0.75}$ & 0.6 & 2.5 & 10.1 & 6.0 & 18.7 \\
$\mathrm{Pd}_{0} \mathrm{Pt}_{1.0}$ & 0 & 3.5 & 15.1 & 8.9 & 12.5
\end{tabular}

$\mathrm{ml} \mathrm{min}{ }^{-1}$ was passed over the samples and the variance rate of temperature was $5 \mathrm{~K} \mathrm{~min}^{-1}$. The sample was heated from room temperature to $1223 \mathrm{~K}$, cooled to $373 \mathrm{~K}$, then heated again to 1223 $\mathrm{K}$, and finally cooled to $373 \mathrm{~K}$. The first and second cycles were mainly used to clean up the surface hydroxyls as well as adsorbed water vapor (see ESI, Fig. S1†). Therefore, the third cycle was used to analysis the phase transformation. The third cycle of these catalysts is shown in Fig. 1. For the Pd catalyst, a typical hysteresis curve for Pd catalysts can be observed in the PdO $\rightarrow$ Pd $\rightarrow$ PdO transformation when sequentially increasing the temperature and then cooling in air, as shown in Fig. 1a. Some scientists ${ }^{22,23}$ also reported that the hysteresis was also observed in the reaction of methane combustion on Pd. The weight of the air exposed catalyst starts to decrease when the temperature reaches around $1080 \mathrm{~K}$, reflecting the onset of the PdO $\rightarrow$ Pd transformation.

In the case of $\mathrm{Pd}_{0.75} \mathrm{Pt}_{0.25}$, the hysteresis still exists. However, the onset transformation temperature decreased to $1020 \mathrm{~K}$, which is lower than that for the Pd catalyst. The onset transformation temperature decreased with the increment of $\mathrm{Pt}$ content. Besides, the Pd-Pt bimetallic catalyst with a higher Pt content exhibited a higher oxygen release onset temperature upon rising temperature. Significantly, the oxygen uptake and release for the Pt-rich catalysts are negligible compared to the other catalysts, reflecting that the Pt atoms in Pt enrichment catalysts will hinder the oxidation of Pd.

The optimized geometries of the oxide phases $\mathrm{Pd}_{x} \mathrm{Pt}_{1-x} \mathrm{O}$ with $x=0,0.25,0.5,0.75$ and 1 are shown in Fig. 2. For each composition and each type, the total energies of all super-cells were calculated to acquire the minimum energy configurations. The minimum formation energies of the $\mathrm{Pd}_{x} \mathrm{Pt}_{1-x} \mathrm{O}$ configuration at $0 \mathrm{~K}$ were calculated to evaluate the thermodynamic stability. Although some previous reports showed that $\mathrm{Pt}_{3} \mathrm{O}_{4}$ and $\mathrm{PtO}_{2}$ phases are thermodynamically stable, only $\mathrm{Pd}_{x} \mathrm{Pt}_{1-x} \mathrm{O}$ phases are detected by XRD, probably due to kinetic reasons. ${ }^{9}$ At the oxygen pressure of $20 \mathrm{kPa}$, PdO decomposes directly into metallic Pd at temperatures higher than $\sim 1056 \mathrm{~K}$ (Fig. 3), which is consistent with the experimental value of $1080 \mathrm{~K}$. Transformation temperature decreased with the increment of Pt content, and the trend is consistent with the experimental results. Also, a high $\mathrm{O}_{2}$ pressure (oxygen chemical potential) aids the formation of metallic oxide $\left(\mathrm{Pd}_{x} \mathrm{Pt}_{1-x} \mathrm{O}\right)$.
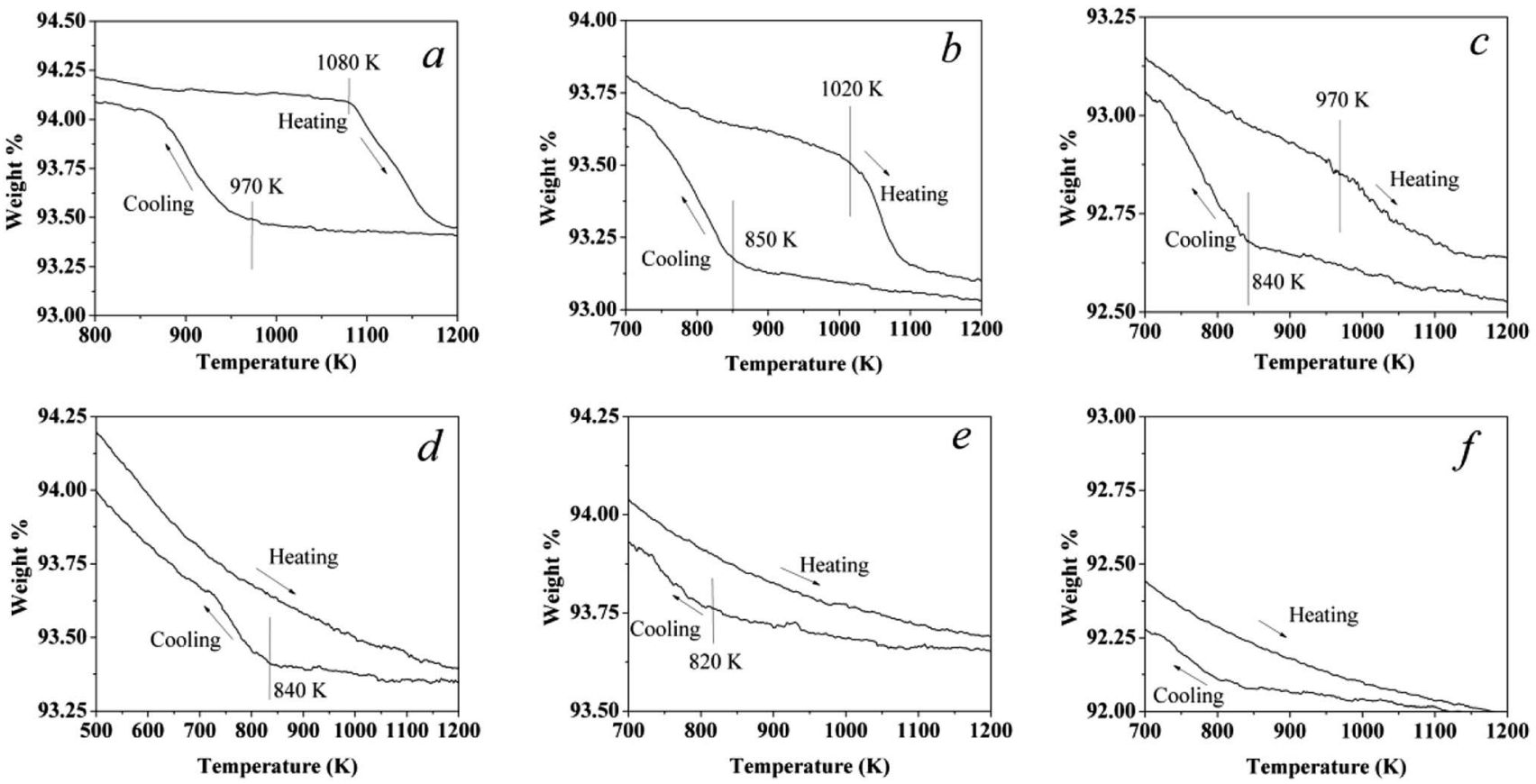

Fig. 1 Third cycle: a TG curing of the catalysts in a flowing $20 \% \mathrm{O}_{2}$ and $80 \% \mathrm{~N}_{2}$ stream at a constant rate of $5 \mathrm{~K} \mathrm{~min}^{-1}$. (a) $\mathrm{Pd}_{1.0} \mathrm{Pt}_{0}$, (b) $\mathrm{Pd}_{0.75} \mathrm{Pt}_{0.25}$, (c) $\mathrm{Pd}_{0.5} \mathrm{Pt}_{0.5}$, (d) $\mathrm{Pd}_{0.25} \mathrm{Pt}_{0.75}$, (e) $\mathrm{Pd}_{0} \mathrm{Pt}_{1.0}$, and (f) a pellet of $\gamma-\mathrm{Al}_{2} \mathrm{O}_{3}$ without $\mathrm{Pd}$ or Pt content. The plots of the first and second cycles are shown in Fig. S1. $\dagger$ 


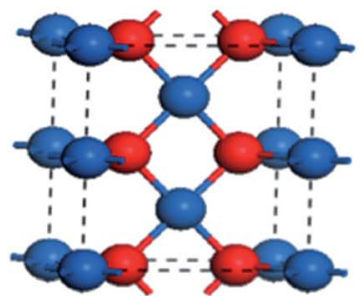

(a)

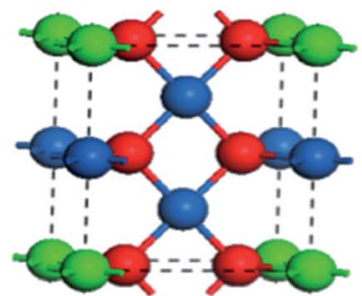

(b)

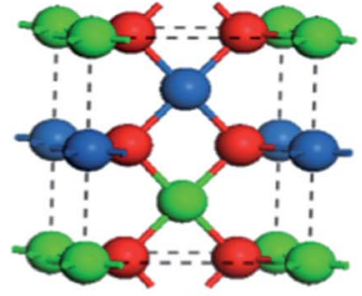

(c)

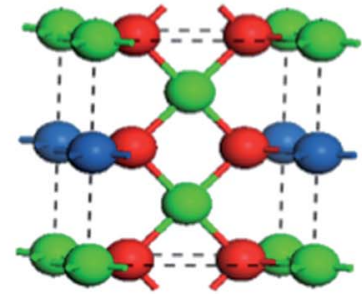

(d)

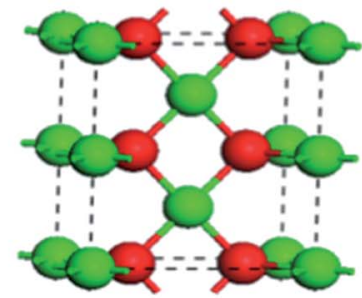

(e)

Fig. 2 Atomic super-cells of $\mathrm{Pd}_{x} \mathrm{Pt}_{x-1} \mathrm{O}$. Blue, green, and red spheres represent $\mathrm{Pt}, \mathrm{Pd}$, and $\mathrm{O}$ atoms, respectively.

\subsection{Kinetic dependence of $\mathrm{CH}_{4}-\mathrm{O}_{2}$ reactions}

For all the experimental conditions, to achieve the same space velocity of $48000 \mathrm{~h}^{-1}$, a continuous flow of gas mixture at 200 $\mathrm{ml} \mathrm{min}{ }^{-1}$ was passed over $0.17 \mathrm{~g}$ of catalyst and $\gamma-\mathrm{Al}_{2} \mathrm{O}_{3}$ powder. The catalyst powders were mixed uniformly with 30 times their amount of $\gamma-\mathrm{Al}_{2} \mathrm{O}_{3}$ to rule out inter-particle heat and mass transfer restrictions. The catalysts were held in place between two layers of quartz wool and a K-type thermocouple was inserted in the packed catalyst bed. All catalyst and $\gamma-\mathrm{Al}_{2} \mathrm{O}_{3}$ powder mixtures were heated at $723 \mathrm{~K}$ with a $10 \% \mathrm{H}_{2} / \mathrm{N}_{2}$ feed for $1 \mathrm{~h}$, and then held in flowing $100 \% \mathrm{~N}_{2}$ for $1 \mathrm{~h}$ before pumping the $\mathrm{CH}_{4} / \mathrm{O}_{2} / \mathrm{N}_{2}$ gas mixture. Every working condition was maintained for $30 \mathrm{~min}$ before the measurement, then another gas component was added and this procedure was repeated. Concentrations of the exhaust gas were measured with gas chromatography.

The reaction rates for methane combustion were acquired via kinetic measurements over a broad range of oxygen (0-30

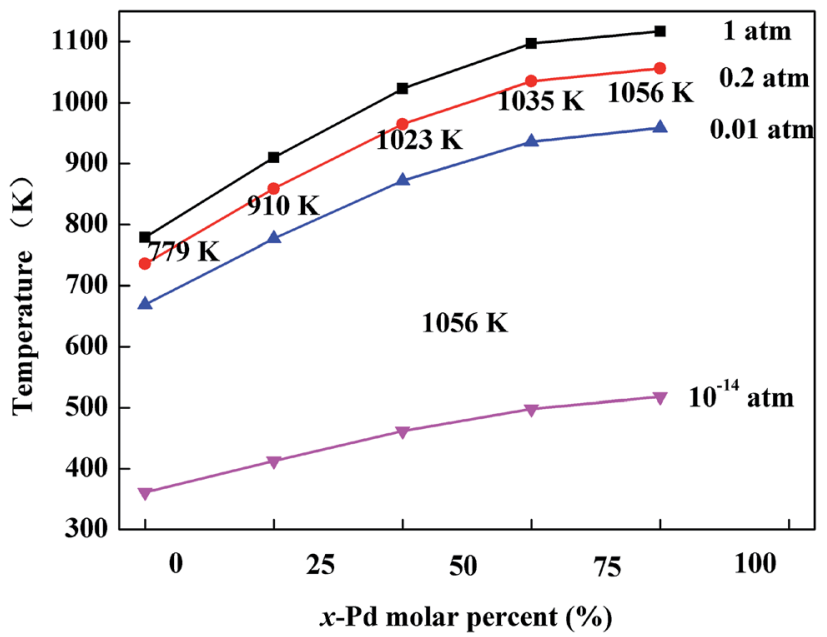

Fig. 3 Variation of phase transition temperature for $\mathrm{Pd}_{x} \mathrm{Pt}_{1-x} \mathrm{O}$ at different oxygen pressures.
$\mathrm{kPa})$ and methane (2, 3 and $4 \mathrm{kPa}$ ) pressures. Fig. 4 shows the first order rate constants for methane combustion as a function of $\mathrm{O}_{2}$ pressure on these catalysts. A rough judgment shows that turnover rates of methane are proportional to methane pressure. For the Pd-containing catalysts, the linear correlation between the first order rate constants and $\mathrm{O}_{2}$ pressure was established under the condition of a high $\mathrm{O}_{2}$ pressure (over 2-6 $\mathrm{kPa}$ ). However, this conclusion is no longer suitable for the Ptcontaining catalysts at low pressure (below 2-6 kPa), and the experimental data at low $\mathrm{O}_{2}$ pressure are irregular.

The turning point of the first order rate constant for these catalysts reflects the different kinetic consequences and the catalytic surfaces at different oxygen chemical potentials. For the Pt-containing catalysts, the first order rate constant as a single valued function of $\mathrm{O}_{2} / \mathrm{CH}_{4}$ ratio (for an oxygen pressure of Pt-containing catalyst in the range of 0 to $\sim 4 \mathrm{kPa}$ ) can be written as follows:

$$
\begin{gathered}
\frac{r_{\mathrm{CH}_{4}}}{\mathrm{CH}_{4}}=k_{\mathrm{I}, \mathrm{app}}\left(\frac{\mathrm{O}_{2}}{\mathrm{CH}_{4}}\right)^{A} \\
\ln \left(\frac{r_{\mathrm{CH}_{4}}}{\mathrm{CH}_{4}}\right)=\ln k_{\mathrm{I}, \mathrm{app}}+A \ln \left(\frac{\mathrm{O}_{2}}{\mathrm{CH}_{4}}\right)
\end{gathered}
$$

where $A$ represents the slope of the straight line shown in Fig. 5. Goodness of Fit $\left(R^{2}\right)$ in these two regimes, I and II, for the Ptcontaining catalysts was over 0.82 . The $\mathrm{O}_{2}$ (a) and $\mathrm{CH}_{4}$ (b) dependence of the rates is listed in Table 2 .

The region in which the first order rate constant increases with $\mathrm{O}_{2} / \mathrm{CH}_{4}$ ratio indicates that the Pt-containing clusters still maintain a metallic surface. Moreover, the phase and structure of these metallic clusters did not change over the range of $\mathrm{O}_{2} /$ $\mathrm{CH}_{4}$ ratios, which is defined here as regime $\mathrm{I}$. When the $\mathrm{O}_{2} / \mathrm{CH}_{4}$ ratio is greater than a specific value (0.08-0.12 for the Ptcontaining catalysts with different contents of $\mathrm{Pt}$ and $\mathrm{Pd}$ ), the first-order rate constant decreases with $\mathrm{O}_{2} / \mathrm{CH}_{4}$ ratio. The Ptcontaining clusters remain metallic meanwhile the $\mathrm{O}^{*}$ coverage of these clusters increases with the increase of $\mathrm{O}_{2} / \mathrm{CH}_{4}$ 

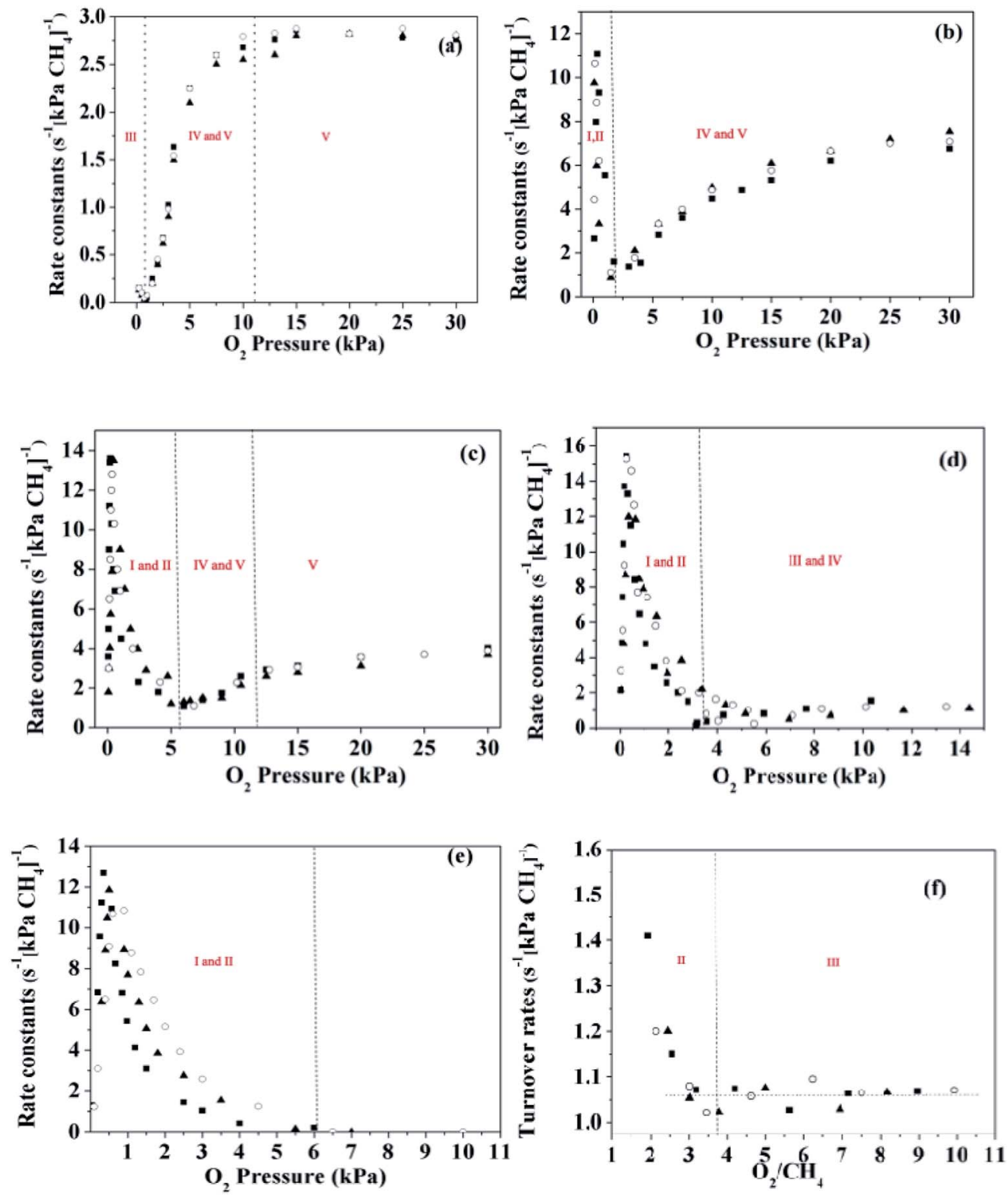

Fig. 4 First order rate constants for methane combustion as a function of $\mathrm{O}_{2}$ pressure on the catalysts at $2 \mathrm{kPa}(\mathrm{O}), 3 \mathrm{kPa}(\boldsymbol{\square})$ and $4 \mathrm{kPa}(\boldsymbol{\Delta})$ ). (a) $\mathrm{Pd}_{1.0} \mathrm{Pt}_{0}-723 \mathrm{~K}$, (b) $\mathrm{Pd}_{0.75} \mathrm{Pt}_{0.25}-723 \mathrm{~K}$, (c) $\mathrm{Pd}_{0.5} \mathrm{Pt}_{0.5}-723 \mathrm{~K}$, (d) $\mathrm{Pd}_{0.25} \mathrm{Pt}_{0.75}-723 \mathrm{~K}$, (e) $\mathrm{Pd}_{0} \mathrm{Pt}_{1.0}-723 \mathrm{~K}$, and (f) $\mathrm{Pd}_{0} \mathrm{Pt}_{1.0}-873 \mathrm{~K}$.

ratio that defines regime II. For the Pt catalyst, $\mathrm{CO}_{2}$ was not detected at the temperature of $723 \mathrm{~K}$ even for a high $\mathrm{O}_{2}$ pressure $(30 \mathrm{kPa})$. However, $\mathrm{CO}_{2}$ could be detected for the temperature of $873 \mathrm{~K}$, suggesting that the first order rate constant for methane combustion is independent of $\mathrm{CH}_{4} / \mathrm{O}_{2}$. Hence, the reaction rates for methane combustion are independent of $\mathrm{O}_{2}$ pressure but proportional to $\mathrm{CH}_{4}$ pressure in regime III $\left(\mathrm{O}_{2} / \mathrm{CH}_{4}>3-4\right)$. For $\mathrm{Pd}_{0.75} \mathrm{Pt}_{0.25}$ and $\mathrm{Pd}_{0.5} \mathrm{Pt}_{0.5}$, the first order rate constant increases with the increment of $\mathrm{O}_{2}$ pressure mainly due to the growing number of active sites (Pd-O). These kinetic interpretations are consistent with all measured rate data and with theoretical estimated overall reaction activation barriers that will be discussed in the next section.

\subsection{Rate equations and their micro-kinetic analysis for $\mathrm{CH}_{4}$ combustion on these catalytic surfaces}

For Pd and Pt catalysts, the kinetic models for methane combustion include three types: Eley-Rideal (ER), LangmuirHinselwood (LH) and Mars-van Krevelen (MvK). In the case of ER mechanisms, an alternative reactant has already been adsorbed on the metallic surface, and the reaction takes place between the adsorbed reactant and another reactant in the gas phase. LH models consider that reactions take place between carbon compounds and oxygen adsorbed on the metallic surface. They describe reactant oxidation over metal oxides via MvK mechanisms. Surface lattice oxygen formed via the dissociation of oxygen from the gas phase. The reactions take place through alternating oxidation and reduction of the catalytic 

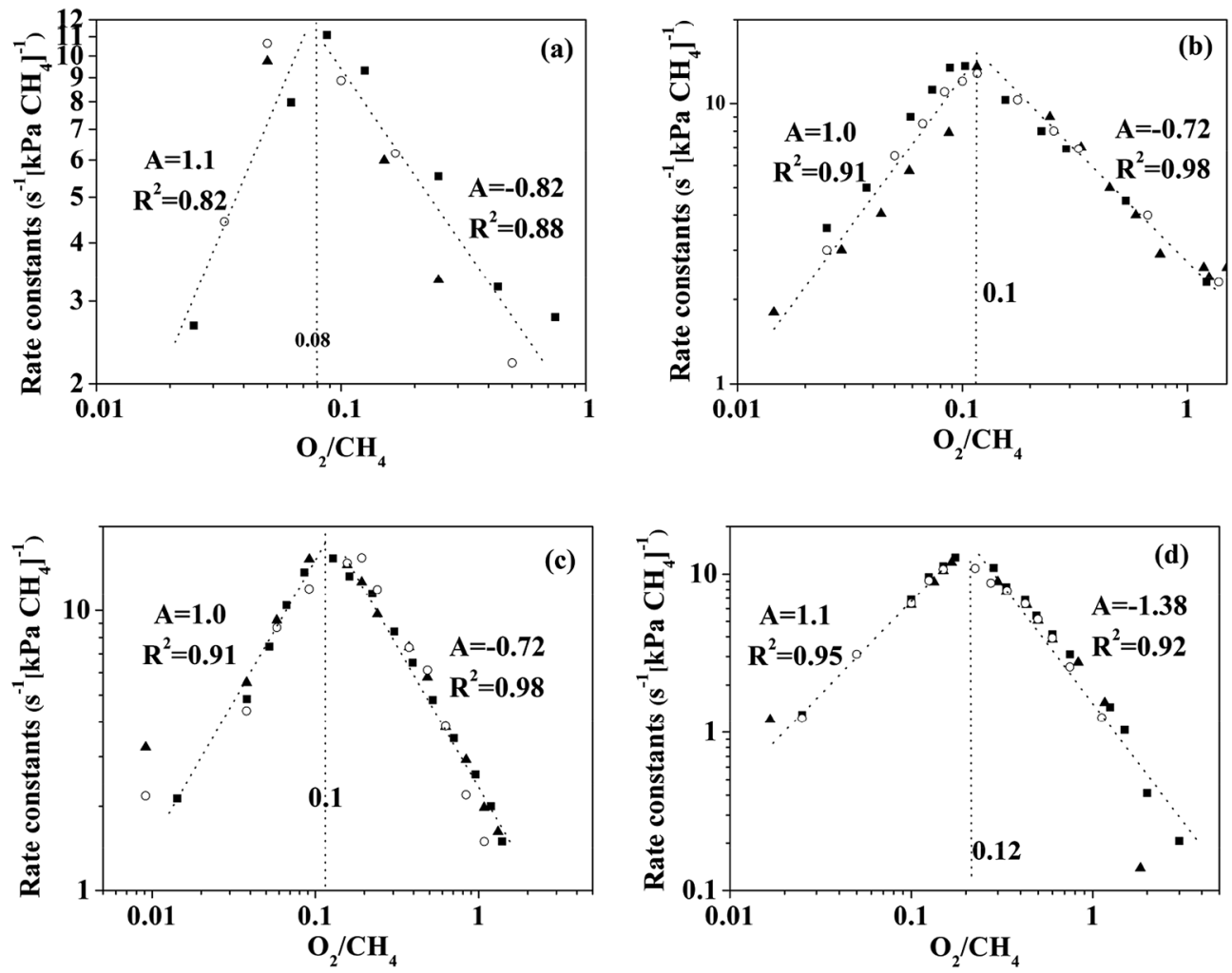

Fig. 5 First-order constant $\left(r_{\mathrm{CH}_{4}}\left(\mathrm{CH}_{4}\right)^{-1}\right)$ for methane oxidation as a single valued function of $\mathrm{O}_{2} / \mathrm{CH}_{4}$ ratio on (a) $\mathrm{Pd}_{0.75} \mathrm{Pt}_{0.25}$, (b) $\mathrm{Pd}_{0.5} \mathrm{Pt}_{0.5}$, (c) $\mathrm{Pd}_{0.25} \mathrm{Pt}_{0.75}$, and $(\mathrm{d}) \mathrm{Pd}_{0} \mathrm{Pt}_{1.0}$. " $A$ " represents the slope of fitting a straight line. The left region and right region of the dash line are regime I and regime II, respectively.

Table 2 The $\mathrm{O}_{2}(\mathrm{a})$ and $\mathrm{CH}_{4}$ (b) dependence of the rates; these values were calculated by using eqn (4) and Fig. $5^{a}$

\begin{tabular}{llllll}
\hline & \multicolumn{2}{c}{ Regime I } & & \multicolumn{2}{l}{ Regime II } \\
\cline { 2 - 3 } \cline { 5 - 6 } Catalyst & $a$ & $b$ & & $a$ & $b$ \\
\hline $\mathrm{Pd}_{0.75} \mathrm{Pt}_{0.25}$ & 1.1 & -0.1 & & -0.82 & 1.82 \\
$\mathrm{Pd}_{0.5} \mathrm{Pt}_{0.5}$ & 1.0 & 0 & & -0.72 & 1.72 \\
$\mathrm{Pd}_{0.25} \mathrm{Pt}_{0.75}$ & 1.0 & 0 & & -0.72 & 1.72 \\
$\mathrm{Pd}_{0} \mathrm{Pt}_{1.0}$ & 1.1 & -0.1 & & -1.38 & 2.38
\end{tabular}

${ }^{a}$ The rates of methane oxidation in regimes I and II can be written as $r_{\mathrm{CH}_{4}}=k_{\text {app }}\left(\mathrm{O}_{2}\right)^{a}\left(\mathrm{CH}_{4}\right)^{b}, a=A$ and $b=-A+1$.

surfaces. Hence, LH and ER models are suitable for Pt while $\mathrm{MvK}$ is likely to occur for Pd since the surface oxidation states were observed under lean conditions. The mechanisms of $\mathrm{O}_{2}$ dissociation and $\mathrm{C}-\mathrm{H}$ bond cleavage on these catalytic surfaces are very different from each other. Elementary steps for $\mathrm{CH}_{4}$ catalytic combustion in different regimes are shown in Table 3.

Six kinds of catalytic surfaces with different oxygen chemical potentials are shown in Fig. 6. In this paper, the types of active sites are respectively expressed as $*_{-} *$ (Fig. 6a), *-O* (Fig. 6b and c), $\mathrm{O}^{*}-\mathrm{O}^{*}$ (Fig. 6d) and $\mathrm{Pd}-\mathrm{O}$ (Fig. 6e and f) for $\mathrm{C}-\mathrm{H}$ bond cleavage with the increase of oxygen chemical potential. The optimized geometry of IS, TS and FS for methane and oxygen dissociation on these surfaces (Fig. S2-S4†) and their parameters (Table $\mathrm{S} 1 \dagger)$ are presented in the ESI. $\dagger$
In our previous study, the activity and stability of methane combustion on these catalysts under methane lean conditions were studied, suggesting that $\mathrm{Pd}_{0.75} \mathrm{Pt}_{0.25}$ was the most promising catalyst. ${ }^{9}$ Generally, a transition in methane conversion reflects the variation of the different kinetic regimes. Here, the measured and calculated activation enthalpies and entropies are compared. These parameters are related to the methane and/or oxygen dissociation rate, according to:

$$
\begin{aligned}
k_{\text {overall }} & =\frac{k_{\mathrm{B}} T}{h} \exp \left(\frac{\Delta S}{R}\right) \exp \left(-\frac{\Delta E_{\text {apparent }}}{R T}\right) \\
& =A_{0} \exp \left(-\frac{\Delta E_{\text {apparent }}}{R T}\right),
\end{aligned}
$$

where $A_{0}$ denotes the pre-exponential factor, $T$ is the temperature, $h$ is the Planck constant and $k_{\mathrm{B}}$ is the Boltzmann constant. Experimental results of the regression fitting of the temperature dependent rate constant for these catalysts are shown in Fig. 7. Reaction rate equations (eqn (6), (8)-(10)) for these different kinetic regimes were obtained by the assumption of different active sites (derived in eqn (S29) $\dagger$ ). The measured apparent activation energies are consistent with the calculated energy barriers of the overall reactions, which are listed in Table 4 . These apparent activation energies reflect the combined effects of the methane and oxygen activation on the different catalytic surfaces. Apparent activation energies were calculated from the reaction rate constants, which were acquired from the reaction rate expressions in every kinetic regime. In this paper, these 
Table 3 Elementary steps for $\mathrm{CH}_{4}$ catalytic combustion in different regimes ${ }^{a}$

\begin{tabular}{|c|c|c|c|}
\hline Classification & Step & Elementary reaction step & $\begin{array}{l}\text { Rate and equilibrium } \\
\text { constant }\end{array}$ \\
\hline \multirow[t]{2}{*}{$\mathrm{O}_{2}$ dissociation } & 1.1 & $\mathrm{O}_{2}+{ }^{*} \rightleftharpoons \mathrm{O}_{2}^{*}$ & $k_{1,1 \mathrm{f}}, k_{1,1 \mathrm{r}}$ \\
\hline & 1.3 & $\mathrm{O}_{2}^{*}+2 \mathrm{~V} \rightleftharpoons 2 \mathrm{~V}_{\mathrm{O}}+*$ & $k_{1,3 \mathrm{f}}, k_{1,3 \mathrm{r}}$ \\
\hline \multirow{2}{*}{$\mathrm{CH}_{4}$ dissociation } & 2.1 & $\mathrm{CH}_{4}+{ }^{*}+{ }^{*} \rightarrow \mathrm{CH}_{3}^{*}+\mathrm{H}^{*}$ & $k_{2,1 \mathrm{f}}$ \\
\hline & 2.2 & $\mathrm{CH}_{4}+*+\mathrm{O}^{*} \rightarrow \mathrm{CH}_{3}^{*}+\mathrm{OH}^{*}$ & $k_{2,2 \mathrm{f}}$ \\
\hline
\end{tabular}

simulations and results of these kinetic regimes are reported in the order of increasing $\mathrm{O}^{*}$ coverage or oxygen chemical potential. We discuss every kinetic regime and give the kinetic interpretation in the below sections.

3.3.1 Methane $\mathrm{C}-\mathrm{H}$ bond cleavage on metallic surfaces without $\mathrm{O}$ coverage $\left(*_{-} *\right.$, in regime $\left.\mathrm{I}\right)$. For low $\mathrm{O}_{2}$ pressure, a massive metallic vacancy forms, nevertheless $\mathrm{O}_{2}$ is lacking since $\mathrm{O}^{*}$ will be immediately depleted by other species. $\mathrm{O}_{2}$ dissociation is irreversible due to the high adsorption energy of $\mathrm{O}$ in this kinetic regime, especially for the clean metallic surfaces (Fig. S3†). Assumptions of irreversible $\mathrm{O}=\mathrm{O}$ and $\mathrm{C}-\mathrm{H}$ bond cleavage lead to rates being proportional to oxygen chemical potential (derived in the ESI, eqn (S16)-(S19)†).
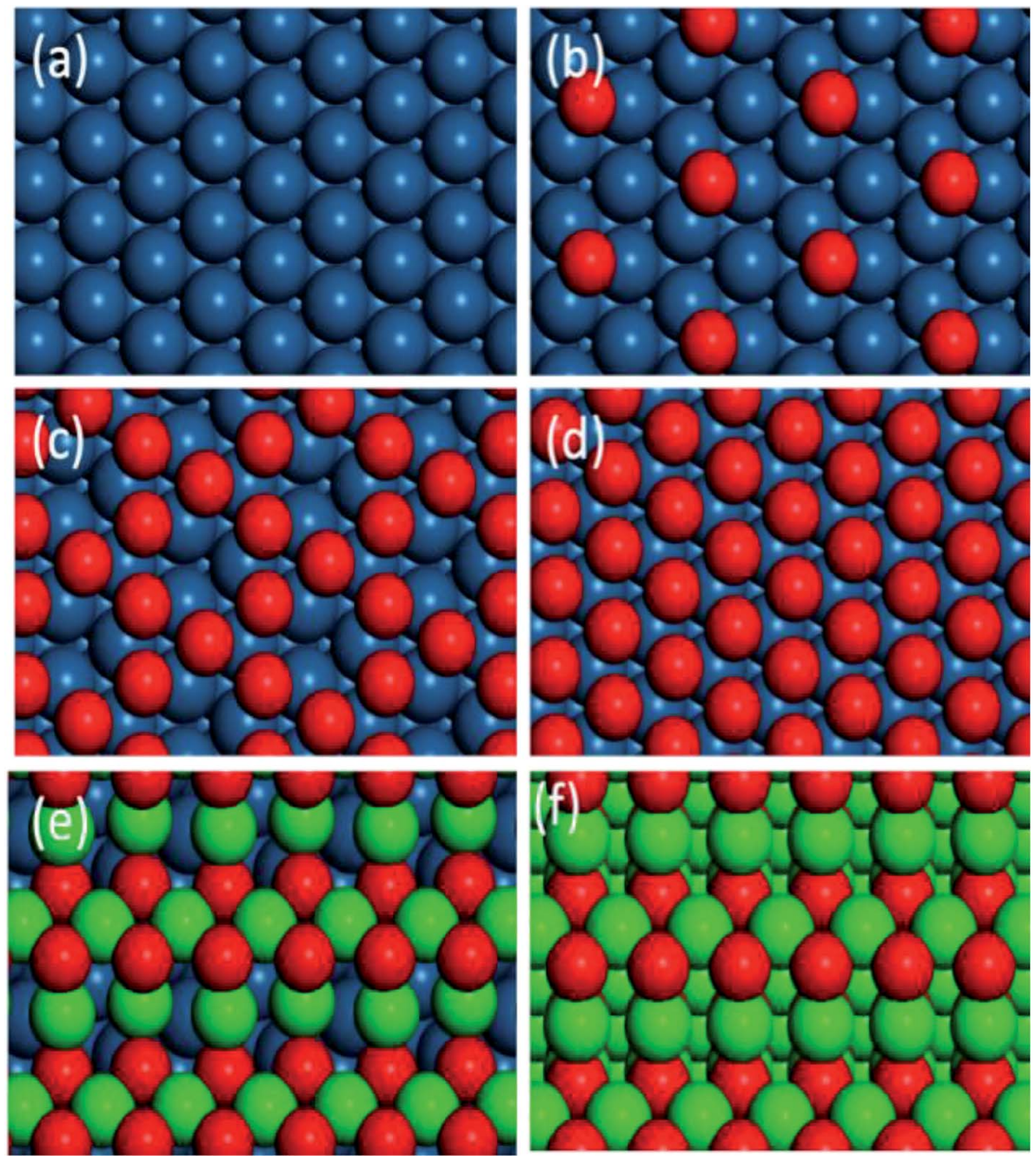

Fig. 6 Optimized structures of different catalytic surfaces. (a) Pt(111), (b) $0.25 \mathrm{ML} \mathrm{O}$, (c) $0.75 \mathrm{MLO}$ and (d) O* saturated on Pt(111) surfaces, (e) monolayer $\mathrm{PdO}(101)$ on $\mathrm{Pt}(100)$ and (f) $\mathrm{PdO}(101)$. 


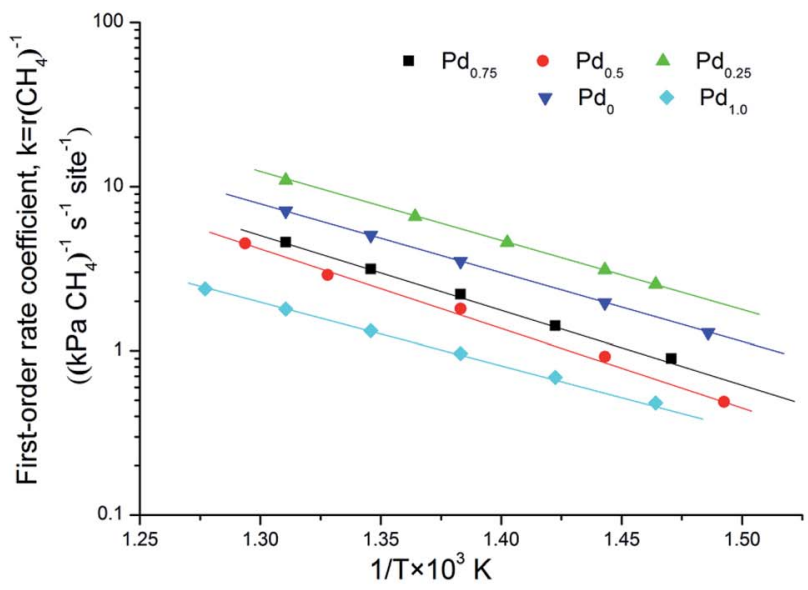

(a)

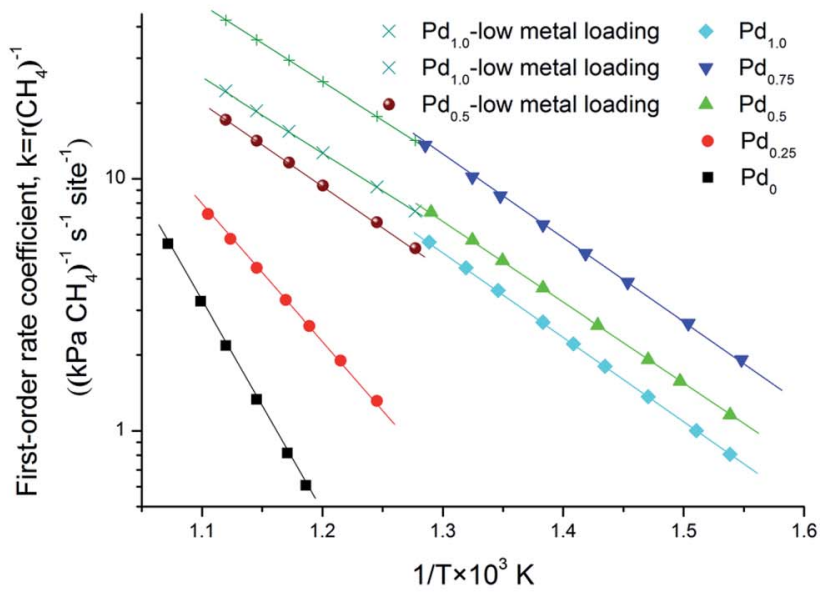

(b)

Fig. 7 Arrhenius plots of the methane first order rate coefficient versus $1000 / T$ for methane combustion on different catalysts. (a) Oxygen pressure at $2 \mathrm{kPa}$ for $\mathrm{Pd}_{0.75} \mathrm{Pt}_{0.25}, \mathrm{Pd}_{0.5} \mathrm{Pt}_{0.5}, \mathrm{Pd}_{0.25} \mathrm{Pt}_{0.75}$ and $\mathrm{Pt}_{1.0}$, and $0.5 \mathrm{kPa}$ for $\mathrm{Pd}_{1.0}$; "low metal loading" means that metal loading is $0.35 \mathrm{wt} \%$; (b) oxygen pressure at $20 \mathrm{kPa}$ for all catalysts. $R$-square values for these experimental data are larger than 0.93 .

$$
r_{*-*}=\frac{k_{1.2 \mathrm{f}} K_{1.1} P_{\mathrm{O}}}{2}
$$

A $2 \times 2$ unit cell consisting of four metallic atom layers was used to model the M(111) surface (Fig. 6a). In this case, enough active metallic vacancies were formed for methane and oxygen dissociation. The calculated activation energy of methane first $\mathrm{C}-\mathrm{H}$ bond dissociation on $\operatorname{Pd}(111)$ and $\operatorname{Pt}(111)$ is 83 and $78 \mathrm{~kJ} \mathrm{~mol}{ }^{-1}$, respectively. Further, the activation energy decreases in the case of the Pd-Pt bimetallic substrate atomic layer (79 and $75 \mathrm{~kJ} \mathrm{~mol}^{-1}$ for Pd/Pd-Pt(111) and Pt/Pd-Pt(111), respectively). The $\mathrm{O}=\mathrm{O}$ activation barrier is much lower due to the high binding energies on clean metallic surfaces, resulting in a strong endothermal reaction for oxygen dissociation. ${ }^{24}$ According to eqn (6), the overall reaction activation energy in regime I can be written as:

$$
\Delta E_{\mathrm{I}}=E_{1,2 \mathrm{f}}+\left(E_{1.1 \mathrm{f}}-E_{1,1 \mathrm{r}}\right)=E_{1.2 \mathrm{f}}-Q_{\mathrm{O}_{2}} .
$$

Hence, the calculated overall reaction activation energy on $\mathrm{Pt}$ in regime $\mathrm{I}$ is $31 \mathrm{~kJ} \mathrm{~mol}^{-1}$, being close to the measured apparent activation energy with a value of $5 \mathrm{~kJ} \mathrm{~mol}^{-1}$ (Table 4). Obviously, this value is much smaller than the value of $\mathrm{C}-\mathrm{H}$ activation energy $\left(73 \mathrm{~kJ} \mathrm{~mol}^{-1}\right)$. Therefore, turnover rates for methane combustion are determined by $\mathrm{O}_{2}$ pressure and independent of methane concentration. Besides, the modeled $\mathrm{Pd} / \mathrm{PtPd}(111)$ and Pt/PtPd(111) surfaces were built as Pd-rich and Pt-rich bimetallic catalytic surfaces, respectively. The differences in methane activation energies at different Pd-Pt (111) facets were minor, with a value difference of only $4 \mathrm{~kJ} \mathrm{~mol}^{-1}$. Besides, the differences between methane activation on $1 \mathrm{ML} \mathrm{O/Pt/PdPt(111)} \mathrm{and}$ $1 \mathrm{ML} \mathrm{O/Pt(111)} \mathrm{were} \mathrm{also} \mathrm{compared,} \mathrm{with} \mathrm{a} \mathrm{difference} \mathrm{value} \mathrm{less}$ than $4 \mathrm{~kJ} \mathrm{~mol}^{-1}$. Hence, the Pd : Pt molar ratio has little effect on the activation energy of methane $\mathrm{C}-\mathrm{H}$ bond cleavage at similar facets.

3.3.2 Methane $\mathbf{C}-\mathbf{H}$ bond cleavage on metallic surfaces at intermediate $\mathrm{O}^{*}$ coverage $\left({ }^{*}-\mathrm{O}^{*}\right.$, in regime $\left.\mathrm{II}\right)$. The transition in methane conversion reflects an increase in oxygen coverage and oxygen and chemical potential, which causes a lack of the paired vacancy *_* and rates to ultimately become limited by methane activation on $\mathrm{O}^{*}{ }^{*}$. In this case, rates are given by (details can be found in the ESI, eqn (S20)-(S23)†):

$$
r_{\mathrm{O}^{*-} *}=\frac{2 k_{2.2 \mathrm{f}}^{2}}{k_{1.2 \mathrm{f}} K_{1.1}} \frac{P_{\mathrm{m}}^{2}}{P_{\mathrm{O}}}
$$

Apparently, the turnover rates for methane combustion in this regime decrease with an increment of $\mathrm{O}_{2}$ pressure (decreasing number of active sites), which has been verified by experiment. $\mathrm{O}^{*}$ coverage increases with increasing oxygen

\begin{tabular}{|c|c|c|c|c|c|}
\hline \multirow{2}{*}{$\begin{array}{l}\text { Kinetic regime } \\
\text { Reaction rate }\end{array}$} & & I & II & III & IV and V \\
\hline & & $k_{1.2 \mathrm{f}} K_{1.1} P_{\mathrm{O}}$ & $2 k_{2.2 \mathrm{f}^{2}} P_{\mathrm{m}}^{2}$ & $k_{2.3 \mathrm{f}} P_{\mathrm{m}}$ & $k_{2.4 \mathrm{f}} P_{\mathrm{m}}$ \\
\hline $\begin{array}{l}\text { Apparent activation energy } \\
\text { Kinetic parameters } \boldsymbol{A}, B(C)\end{array}$ & & $E_{1.2 \mathrm{f}}-Q_{\mathrm{O}_{2}}$ & $\begin{array}{l}k_{1.2 \mathrm{f}} K_{1.1} P_{\mathrm{O}} \\
2 E_{2.2 \mathrm{f}}-\left(E_{1.2 \mathrm{f}}-Q_{\mathrm{O}_{2}}\right)\end{array}$ & $\begin{array}{l}E_{2.3 \mathrm{f}} \\
\mathbf{1 . 5} \times \mathbf{1 0}^{\mathbf{1 0}}, 145(163)\end{array}$ & $\begin{array}{l}E_{2.4 \mathrm{f}} \\
\mathbf{5 . 8} \times 10^{5}, 65(61)\end{array}$ \\
\hline & $\mathrm{Pd}_{0.75} \mathrm{Pt}_{0.25}$ & 92,8 & $8.4 \times 10^{6}, 87(81)$ & & $8.2 \times 10^{5}, 62$ \\
\hline & $\mathrm{Pd}_{0.5} \mathrm{Pt}_{0.5}$ & 148,12 & $9.2 \times 10^{6}, 89$ & & $4.4 \times 10^{5}, 62(67)$ \\
\hline & $\mathrm{Pd}_{0.25} \mathrm{Pt}_{0.75}$ & 248,15 & $\mathbf{5 . 6} \times \mathbf{1 0}^{\mathbf{6}}, \mathbf{7 9}(79)$ & & $1.9 \times 10^{7}, 101(110)$ \\
\hline
\end{tabular}

Table 4 Comparison between apparent activation energy and activation energy of the overall reaction: $A, B$, and $C$ represent pre-exponential factor, measured apparent activation energy and DFT-calculated activation energy for overall reaction, respectively 
pressure. For low $\mathrm{O}^{*}$ coverage $(0.25 \mathrm{ML} \mathrm{O})$, methane dissociation occurs on $\mathrm{O}^{*}{ }^{*}$ with an activation barrier of 118 and $105 \mathrm{~kJ} \mathrm{~mol}^{-1}$ for $\mathrm{Pt}(111)$ and $\mathrm{Pd}(111)$, respectively. The atomic model of 0.75 ML O monolayer was chosen to express the higher oxygen coverage. The adsorption energy of $\mathrm{O}$ decreases with the increment of $\mathrm{O}^{*}$ coverage, leading to more active adsorption oxygen atoms (higher adsorption energy of $\mathrm{H}$ ). Meanwhile, high atomic oxygen coverage increases the coordination number of the metal atoms, which makes the $\mathrm{C}-\mathrm{H}$ bond activation barriers higher.

In this kinetic regime, the apparent activation energies reflect the collective effects of the $\mathrm{O}_{2}^{*}$ dissociation barrier, the $\mathrm{C}-\mathrm{H}$ activation energies on $\mathrm{O}^{*}{ }^{*}$ and the heat of $\mathrm{O}_{2}$ adsorption. Although their contributions cannot be measured by experiments, DFT calculations of methane activation on $\mathrm{O}^{*} *$ could provide significant evidence in this matter. According to eqn (8), the overall reaction activation energy in regime II can be given by:

$$
\Delta E_{\mathrm{II}}=2 E_{2.2 \mathrm{f}}-\left(E_{1.2 \mathrm{f}}-Q_{\mathrm{O}_{2}}\right)
$$

3.3.3 Methane $\mathrm{C}-\mathrm{H}$ bond cleavage on metallic surfaces completely covered by $\mathrm{O}^{*}\left(\mathrm{O}^{*}-\mathrm{O}^{*}\right.$, in regime $\left.\mathrm{III}\right)$. In the case of the kinetic regime III, the number of active sites $\left(\mathrm{O}^{*}-\mathrm{O}^{*}\right)$ did not change; the methane combustion rate was no longer affected by $\mathrm{O}_{2}$ pressure. Apparent energies in this regime were only determined by $\mathrm{C}-\mathrm{H}$ bond activation barriers on $\mathrm{O}^{*}-\mathrm{O}^{*}$ paired sites. For the Pt catalyst, the turnover rate of methane ultimately dropped to a constant value, which did not vary with $\mathrm{O}_{2}$ pressure. Experimental results showed that the number of active sites no longer changed. ${ }^{25,26}$ These data indicate that turnover rates can be described by a simple rate equation in regime III (see ESI, eqn (S24)-(S26) †):

$$
r_{\mathrm{O} * \mathrm{O}} *=k_{2.3 \mathrm{f}} P_{\mathrm{m}},
$$

where $k_{2.3 \mathrm{f}}$ is the rate constant for the first $\mathrm{C}-\mathrm{H}$ bond cleavage of methane on $\mathrm{O}^{*}-\mathrm{O}^{*}$. According to eqn (10), the overall reaction activation energy in regime III can be given by:

$$
\Delta E_{\mathrm{III}}=E_{2.3 \mathrm{f}}
$$

For the $\mathrm{O}^{*}$ saturated surface, paired $\mathrm{O}^{*}-\mathrm{O}^{*}$ sites are formed for methane dissociation instead of the paired $\mathrm{O}^{*_{-} *}$ and $*_{-} *$ sites. Chin et al. ${ }^{25}$ reported that $\mathrm{O}^{*}$ coverage depends only on $\mathrm{O}_{2}$ pressure, whether $\mathrm{CH}_{4}$ exists or not. Although the activation energy barrier for $\mathrm{O}=\mathrm{O}$ bond cleavage is higher than that for the $\mathrm{C}-\mathrm{H}$ bond (228 vs. $175 \mathrm{~kJ} \mathrm{~mol}^{-1}$ ), the advantage of high oxygen coverage makes the elementary reaction $\mathrm{C}-\mathrm{H}$ bond cleavage, which is the RDS. Clearly, the $\mathrm{C}-\mathrm{H}$ activation barrier on $\mathrm{O}^{*}-\mathrm{O}^{*}$ is higher than that on $\mathrm{O}^{*}{ }^{*}$ due to the weaker $\mathrm{C}-\mathrm{O}$ bond strength compared to the $\mathrm{C}-\mathrm{Pd}$ and/or $\mathrm{C}-\mathrm{Pt}$ bond, resulting in the poor activity for methane lean combustion on the Pt catalyst and rich combustion on the Pd catalyst. Besides, the apparent energy for the Pd-Pt bimetallic catalysts in kinetic regime III is difficult to measure even under the condition of higher temperature due to the interference of regimes IV and V.
The measured apparent activation energy $\left(81 \mathrm{~kJ} \mathrm{~mol}^{-1}\right)$ for methane combustion over Pt in regime III is consistent with the DFT calculated value $\left(77 \mathrm{~kJ} \mathrm{~mol}^{-1}\right)$. This kinetic interpretation is also suitable for the low pressure region of methane combustion on the $\mathrm{Pd}$ catalyst.

3.3.4 Methane $\mathrm{C}-\mathrm{H}$ bond cleavage on metallic oxide surfaces (Pd-O, in regimes IV and V). Pd atoms more easily segregate on the Pd-Pt bimetallic surface compared to Pt and then a Pd monolayer oxide is formed under the condition of high $\mathrm{O}_{2}$ pressure in kinetic regime IV. Our DFT results indicate that monolayer Pd oxide has poor activity, while the activity of the two monolayer Pd oxide was greatly improved $(110 \rightarrow$ $67 \mathrm{~kJ} \mathrm{~mol}^{-1}$ ). Although the monometallic Pt catalyst is hard to oxidize at high temperature, the monometallic Pd catalyst can maintain the oxide states even at high temperature. ${ }^{27,28}$ Extensive research has shown that methane activation takes place on a paired $\mathrm{Pd}-\mathrm{O}$ site. Bossch et al. ${ }^{29}$ showed that $\mathrm{O}_{2}$ would be better adsorbed by Pd atoms, and thereafter $\mathrm{O}_{2}^{*}$ would dissociate into the oxygen vacancy. Gremminger et al. ${ }^{30}$ showed that for $\mathrm{Pd}-\mathrm{Pt} / \mathrm{Al}_{2} \mathrm{O}_{3}$ catalysts under lean combustion conditions, $\mathrm{Pd}$ segregates to the surface of the bimetallic clusters. Barcaro et $a .^{31}$ reported that $\mathrm{Pt}$ segregation takes place in the (111) surface while Pd segregation takes place in (100) facets in the case of the optimal $\mathrm{Pd}_{135} \mathrm{Pt}_{48}$ and $\mathrm{Pd}_{110} \mathrm{Pt}_{91}$ clusters. The segregation of $\mathrm{Pd}$ in the (100) facets could promote the formation of $\operatorname{PdO}(101) .{ }^{32,33}$ The kinetic parameters in this regime are difficult to measure due to the interference of Pd oxide for the Pd-rich catalysts. However, the pre-exponential factor and measured apparent activation energy of $\mathrm{Pd}_{0.25} \mathrm{Pt}_{0.75}$ at high oxygen pressure are very different to those of $\operatorname{Pd}_{0.5} \mathrm{Pd}_{0.5}$, $\mathrm{Pd}_{0.75} \mathrm{Pt}_{0.75}$ and Pd. Furthermore, the measured apparent activation energy of $\mathrm{Pd}_{0.25} \mathrm{Pt}_{0.75}$ is $101 \mathrm{~kJ} \mathrm{~mol}^{-1}$, which is close to the value of the calculated value $\left(110 \mathrm{~kJ} \mathrm{~mol}^{-1}\right)$. Hence, the formation of monolayer PdO for the Pt-rich catalysts leads to the low activity of methane combustion.

In the case of kinetic regime $\mathrm{V}$, active sites were stable, and they did not vary with $\mathrm{O}_{2}$ pressure. Hence, the reaction rate of methane remained at a constant value in this kinetic regime. Both the $\mathrm{O}_{2}$ dissociation and $\mathrm{C}-\mathrm{H}$ bond dissociation of methane on $\mathrm{Pd}-\mathrm{O}$ pairs are irreversible in regimes IV and V. Therefore, the reaction rate only related to the partial pressure of methane, given by

$$
r_{\mathrm{Pd}-\mathrm{O}}=k_{2.4 \mathrm{f}} P_{\mathrm{m}}
$$

Hence, the overall reaction activation energy in regimes IV and $\mathrm{V}$ for the oxide surfaces can be given by:

$$
\Delta E_{\mathrm{IV}, \mathrm{V}}=E_{2.4 \mathrm{f}}
$$

Pd atoms in Pd-containing catalysts more easily segregate to the surfaces of clusters at high $\mathrm{O}_{2}$ pressure. ${ }^{34}$ For this reason, the oxide layers exist at high oxygen chemical potential for the Pd-containing catalysts. The $\mathrm{C}-\mathrm{H}$ activation barrier on monolayer oxide $\mathrm{PdO}(101) / \mathrm{Pt}(100)$ is smaller than that on $\mathrm{O}^{*}-\mathrm{O}^{*}$ paired sites $\left(110 \mathrm{~kJ} \mathrm{~mol}^{-1}\right.$ vs. $163 \mathrm{~kJ} \mathrm{~mol}^{-1}$ for $\mathrm{O}^{*}$ saturated $\operatorname{Pd}(111))$. However, this value is much higher than that of 
$\mathrm{PdO}(101)\left(61 \mathrm{~kJ} \mathrm{~mol}^{-1}\right)$. Besides, the activation energy for two mono-layers of $\mathrm{PdO}(101)$ on $\mathrm{Pt}(100)$ is retained with a value of $67 \mathrm{~kJ} \mathrm{~mol}^{-1}$, indicating that activation of Pd-containing catalysts is mainly determined by the two outmost oxide layers. For the Pd-rich catalysts, multiple Pd oxide layers are easily formed, resulting in a high activity for methane combustion in the case of high oxygen pressure.

\section{Conclusion}

The kinetic consequences of $\mathrm{C}-\mathrm{H}$ cleavage for $\mathrm{CH}_{4}-\mathrm{O}_{2}$ on bimetallic platinum-palladium catalysts were investigated in this study. Methane combustion at different $\mathrm{O}_{2}$ pressures was divided into five kinetic regimes. These kinetic regimes exhibit different kinetic dependences and unique rate equations. Methane activation occurs on two adjacent metal sites (*_*), metal site and oxygen ion site pairs $\left(\mathrm{O}^{*}{ }^{*}\right)$, two adjacent oxygen sites $\left(\mathrm{O}^{*}-\mathrm{O}^{*}\right)$, and $\mathrm{Me}-\mathrm{O}$ site pairs located on a metallic cluster and/or oxide cluster. $\mathrm{C}-\mathrm{H}$ bond cleavage on these different active sites has markedly different entropies and activation energies, as confirmed here from measurement and calculation. In the narrow regime $\mathrm{I}, \mathrm{O}_{2}$ species were almost completely depleted, $\mathrm{C}-\mathrm{H}$ cleavage becomes kinetically irrelevant and $\mathrm{O}=\mathrm{O}$ bond cleavage $/ \mathrm{O}_{2}$ supply on $\mathrm{Pd}-\mathrm{Pt}$ clusters limits the turnover rate of methane. The measured apparent activation energies are in the range of $8-15 \mathrm{~kJ} \mathrm{~mol}^{-1}$, which are much smaller than the energy barrier of methane dissociation on $\mathrm{Pd}-\mathrm{Pt}(111)$ clusters. The barriers for $\mathrm{C}-\mathrm{H}$ bond cleavage on *-* range from 75 to $79 \mathrm{~kJ} \mathrm{~mol}^{-1}$, depending on the Pd : Pt mole ratio. Clearly, the supply of oxygen is insufficient due to the low oxygen pressure in this regime. $\mathrm{C}-\mathrm{H}$ bond cleavage is kinetically relevant in the other four regimes, yet it proceeds via different paths on these different site pairs, depending on oxygen pressure and Pd : Pt mole ratio.

$\mathrm{C}-\mathrm{H}$ bond cleavage on $\mathrm{O}^{*-*}$ proceeds via a hydrogen abstraction route that produces $\mathrm{OH}^{*}$ and $\mathrm{CH}_{3}^{*}$. The binding strength of $\mathrm{CH}_{3}^{*}$ is correlated with the coverage of oxygen, which influences the energy barriers for $\mathrm{C}-\mathrm{H}$ bond cleavage on $\mathrm{O}^{*-*}$. Hence, the energy barrier for $\mathrm{C}-\mathrm{H}$ bond cleavage on $\mathrm{O}^{*-*}$ increases with increasing $\mathrm{O}^{*}$ coverage. The kinetic parameters for $\mathrm{C}-\mathrm{H}$ bond cleavage on $\mathrm{O}^{*}-\mathrm{O}^{*}$ in kinetic regime $\mathrm{III}$ are difficult to measure due to the interference of $\mathrm{C}-\mathrm{H}$ bond cleavage on $\mathrm{Pd}-\mathrm{O}$ in kinetic regimes IV and V. However, these parameters could be measured via methane activation on $\mathrm{O}^{*}-$ $\mathrm{O}^{*}$ at the surface of Pt catalysts, the energy barrier of which is much higher than that on $\mathrm{O}$ partially covered surfaces. In contrast, Pd-Pt oxide clusters expose stoichiometric metal atoms and lattice $\mathrm{O}$ ions for $\mathrm{C}-\mathrm{H}$ bond cleavage, which is more effective than $\mathrm{O}^{*-*}$ or $\mathrm{O}^{*}-\mathrm{O}^{*}$. Lattice oxygen ions on $\mathrm{Pd}-\mathrm{Pt}$ oxide surfaces show lower affinity toward $\mathrm{H}$. However, the binding energy of $\mathrm{CH}_{3}-\mathrm{Pd}$ on $\mathrm{Pd}-\mathrm{Pt}$ oxide surfaces is much larger than those on Pd-Pt vacancy sites, resulting in a lower energy barrier. Hence, turnover rates for methane on Pd-Pt increase with the increase of oxygen pressure in kinetic regimes IV and $\mathrm{V}$.

\section{Conflicts of interest}

There are no conflicts to declare.

\section{Acknowledgements}

Financial assistance from the National Natural Science Foundation of China (Nos. 51276207 and 50876118) is gratefully acknowledged. We also would like to thank Open Fund of Fujian Province University Key Laboratory of Green Energy and Environment Catalysis (No. FJ-GEEC201803).

\section{References}

1 A. Abbin, A. Aravind and J. F. Weaver, Pathways and kinetics of methane and ethane $\mathrm{C}-\mathrm{H}$ bond cleavage on $\mathrm{PdO}(101), \mathrm{J}$. Chem. Phys., 2013, 139, 104702-104713.

2 Z. J. Zhao, C. C. Chiu and J. Gong, Molecular understandings on the activation of light hydrocarbons over heterogeneous catalysts, Chem. Sci., 2015, 6, 4403-4425.

3 C. K. Ande, S. D. Elliott and W. M. M. Kessels, First-principles investigation of $\mathrm{C}-\mathrm{H}$ bond scission and formation reactions in ethane, ethene, and ethyne adsorbed on Ru (0001), J. Phys. Chem. C, 2014, 118(46), 26683-26694.

4 J. F. Weaver, H. Can, A. Abbin and A. Aravind, High selectivity for primary $\mathrm{C}-\mathrm{H}$ bond cleavage of propane $\sigma$-complexes on the PdO(101) surface, J. Am. Chem. Soc., 2011, 133, 1619616200.

5 K. Persson, K. Jansson and S. G. Järås, Characterisation and microstructure of Pd and bimetallic Pd-Pt catalysts during methane oxidation, J. Catal., 2007, 245, 401-414.

6 R. Abbasi, L. Wu, S. E. Wanke and R. E. Hayes, Kinetics of methane combustion over Pt and Pt-Pd catalysts, Chem. Eng. Res. Des., 2012, 90, 1930-1942.

7 D. L. Mowery and R. L. Mccormick, Deactivation of alumina supported and unsupported PdO methane oxidation catalyst: the effect of water on sulfate poisoning, Appl. Catal., B, 2001, 34, 287-297.

8 J. C. V. Giezen, F. R. V. D. Berg, J. L. Kleinen, A. J. V. Dillen and J. W. Geus, The effect of water on the activity of supported palladium catalysts in the catalytic combustion of methane, Catal. Today, 1999, 47, 287-293.

9 W. Qi, J. Ran, X. Du, R. Wang, J. Shi, J. Niu, P. Zhang and M. Ran, Kinetics Consequences of Methane Combustion on Pd, Pt and Pd-Pt Catalysts, RSC Adv., 2016, 6, 109834109845.

$10 \mathrm{H}$. Li, Z. Zhang and Z. Liu, Application of Artificial Neural Networks for Catalysis: A Review, Catalysts, 2017, 7, 306.

11 C. Shen, Z. Liu, Z. Wang, J. Guo, H. Zhang, Y. Wang, J. Qin, H. Li, M. Fang and Z. Tang, Building CT Radiomics Based Nomogram for Preoperative Esophageal Cancer Patients Lymph Node Metastasis Prediction, Trans. Oncol., 2018, 11, 815-824.

12 V. R. Choudhary, B. Prabhakar, A. M. Rajput and A. S. Mamman, Oxidative conversion of methane to $\mathrm{CO}$ and $\mathrm{H} 2$ over $\mathrm{Pt}$ or $\mathrm{Pd}$ containing alkaline and rare earth oxide catalysts, Fuel, 1998, 77, 1477-1481. 
13 S. Nicola, P. Wolfgang and C. Lucio Colombi, Catalytic Oxidation Activity of $\mathrm{Pt}_{3} \mathrm{O}_{4}$ Surfaces and Thin Films, $J$. Phys. Chem. B, 2010, 37, 14860-14869.

14 T. Watanabe, K. Kawashima, Y. Tagawa, K. Tashiro, H. Anoda, K. Ichioka, S. Sumiya and G. Zhang, New DOC for Light Duty Diesel DPF System, Eng. Fract. Mech., 2007, 114, 12-25.

15 A. Maione and P. Ruiz, Structured Pd/gamma-Al $2 \mathrm{O} \sim 3$ catalysts on FeCrAlloy fibers for total combustion of methane, Appl. Catal., B, 2007, 75, 59-70.

16 F. H. Hayes and O. Kubaschewski, The Heats of Formation in the System Gold-Platinum-Palladium, Met. Sci. J., 1971, 5, 37-40.

17 G. S. Bugosh, V. G. Easterling, I. A. Rusakova and M. P. Harold, Anomalous steady-state and spatio-temporal features of methane oxidation on $\mathrm{Pt} / \mathrm{Pd} / \mathrm{Al}_{2} \mathrm{O}_{3}$ monolith spanning lean and rich conditions, Appl. Catal., B, 2015, 165, 68-78.

18 B. Delley, Fast Calculation of Electrostatics in Crystals and Large Molecules, J. Phys. Chem., 1996, 100, 6107-6110.

19 Q. Qi, X. Wang, L. Chen and B. Li, Methane dissociation on $\operatorname{Pt}\left(\begin{array}{lll}1 & 1 & 1\end{array}\right), \operatorname{Ir}\left(\begin{array}{lll}1 & 1 & 1\end{array}\right)$ and $\operatorname{Pt} \operatorname{Ir}\left(\begin{array}{lll}1 & 1 & 1\end{array}\right)$ surface: A density functional theory study, Appl. Surf. Sci., 2013, 284, 784-791.

20 A. Dianat, N. Seriani, M. Bobeth, W. Pompe and L. C. Ciacchi, DFT Study of the Thermodynamic Stability of Pd-Pt Bulk Oxide Phases, J. Phys. Chem. C, 2008, 112, 13623-13628.

21 K. Reuter and M. Scheffler, Composition, structure and stability of RuO_2(110) as a function of oxygen pressure, Phys. Rev. B: Condens. Matter, 2001, 65, 321-325.

22 A. K. Datye, J. Bravo, T. R. Nelson, P. Atanasova, M. Lyubovsky and L. Pfefferle, Catalyst microstructure and methane oxidation reactivity during the $\mathrm{Pd} \leftrightarrow \mathrm{PdO}$ transformation on alumina supports, Appl. Catal., A, 2000, 198, 179-196.

23 G. B. Hoflund, H. A. E. Hagelin, J. F. Weaver and G. N. Salaita, ELS and XPS study of Pd/PdO methane oxidation catalysts, Appl. Surf. Sci., 2003, 205, 102-112.

24 H. Li, L. Luo, P. Kunal, C. S. Bonifacio, Z. Duan, J. Yang, S. M. Humphrey, R. M. Crooks and G. Henkelman, Oxygen
Reduction Reaction on Classically Immiscible Bimetallics: A Case Study of RhAu, J. Phys. Chem. C, 2018, 122, 2712-2716. 25 Y. H. Chin, C. Buda, M. Neurock and E. Iglesia, Reactivity of chemisorbed oxygen atoms and their catalytic consequences during CH4-O2 catalysis on supported Pt clusters, J. Am. Chem. Soc., 2011, 133, 15958-15978.

$26 \mathrm{~W}$. Tu and Y. H. Chin, Catalytic consequences of the identity and coverages of reactive intermediates during methanol partial oxidation on Pt clusters, J. Catal., 2014, 313, 55-69.

27 H. Xiong, K. Lester, T. Ressler, R. Schlögl, L. F. Allard and A. K. Datye, Metastable Pd $\leftrightarrow$ PdO Structures During High Temperature Methane Oxidation, Catal. Lett., 2017, 147, 1095-1103.

28 Y. H. Chin, M. Garcíadiéguez and E. Iglesia, Dynamics and Thermodynamics of Pd-PdO Phase Transitions: Effects of Pd Cluster Size and Kinetic Implications for Catalytic Methane Combustion, J. Phys. Chem. C, 2016, 120, 14461460.

29 M. V. D. Bossche and H. Grönbeck, Methane Oxidation over PdO(101) Revealed by First-Principles Kinetic Modeling, $J$. Am. Chem. Soc., 2015, 137, 12035-12044.

30 A. T. Gremminger, R. Popescu, J. D. Grunwaldt and O. Deutschmann, Influence of gas composition on activity and durability of bimetallic $\mathrm{Pd}-\mathrm{Pt} / \mathrm{Al}_{2} \mathrm{O}_{3}$ catalysts for total oxidation of methane, Catal. Today, 2015, 258, 470-480.

31 G. Barcaro, A. Fortunelli, M. Polak and L. Rubinovich, Patchy multishell segregation in Pd-Pt alloy nanoparticles, Nano Lett., 2011, 11, 1766.

32 J. G. Mccarty, Kinetics of PdO combustion catalysis, Catal. Today, 1995, 26, 283-293.

33 M. Todorova, E. Lundgren, V. Blum, A. Mikkelsen, S. Gray, J. Gustafson, M. Borg, J. Rogal, K. Reuter and J. N. Andersen, The $\operatorname{Pd}(100)-(5 \times 5) R 27^{\circ}-\mathrm{O}$ surface oxide revisited, Surf. Sci., 2003, 541, 101-112.

34 L. C. A. V. D. Oetelaar, O. W. Nooij, S. Oerlemans, A. W. D. V. D. Gon, H. H. Brongersma, L. Lefferts, A. G. Roosenbrand and J. A. R. V. Veen, Surface Segregation in Supported Pd-Pt Nanoclusters and Alloys, $J$. Phys. Chem. B, 1998, 102, 3445-3455. 